\title{
CULPRIT VERSUS CULPRIT AND NON- CULPRIT PRIMARY CORONARY REVASCULARIZATION
}

\author{
Aly M. Saad*, MD; Mesbah T. Hassanien*, MD; El-Sayed M. Farag*, MD; Hatem K. Madkour**, \\ M.Sc. \\ * Cardiology Department Zagazig University Hospital, ** National Heart Institute
}

\begin{abstract}
Background: Primary percuteneous coronary intervention (PPCI) is the prefered strategy for acute ST segment elevation myocardial inferction (STEMI). CAD is a diffuse process and patients presenting with a coronary syndrome in 20- $40 \%$ of cases have multiple significant coronary lesions, which confer a substantially increased risk of cardiovascular morbidity and mortality. Recent studies suggest that acute coronary syndromes, including AMI, may result from a systemic inflammatory process, causing multiple unstable lesions. Thus, a strategy of multivessel PCI in the peri-infarct period may be important in improving the outcomes of primary angioplasty. Such an attempt of complete revascularization may prevent recurrent ischemia from 'non-infarct-related' lesions, obviating the need for repeat angiography and intervention, and also possibly improves the late outcome by reducing the ischemic burden following myocardial damage. Contemporary guidelines recommend dilating only the infarcted related artery (IRA) during the urgent procedure, leaving the other stenosed vessels untreated "culprit-only revascularisation" (COR) or to dilate during a second elective procedure (staged revascularisation). Simultaneous treatment of IRA and non-IRA is recommended only in patients with cardiogenic shock. However, these guidelines are based on the results of earlier studies. With advancing technology and newer antiplatelet drugs, outcomes have improved even in patients undergoing multivessel and higher-risk elective procedures. Therefore, the optimal management of patients with multivessel disease in this setting still unclear.

Aim of the Work: to compare between primary PCI for culprit lesion only and that for both culprit and non culprit lesion in ST segment elevation MI patients with multi-vessel disease.

Patients and methods: this study concluded 50 patients with acute ST segment elevation myocardial infarction (STEMI) eligible for primary PCI and the patients were devided into two groups: $1^{\text {st }}$ group: 25 patients were managed by primary percutaneous coronary intervention for infarct related artery only "culprit only revascularization" $(\mathrm{COR}) .2^{\text {nd }}$ group: 25 patients were managed by primary percutaneous coronary intervention for infarct related artery and non infart related artery "total revascularization" (TR). All patients had done transthorthic echocardiography during admission and after six months to assess ejection fraction.

Results: During follow up period 52\% of patients in COR group had recurrent angina and chest pain while in TR group 36\% of the patients had recurrent angina and chest pain with p-value 0.039 . In culprit only revascularization group contrast induced nephropathy occur in $12 \%$ of patients while in total revascularization group $36 \%$ had contrast induced nephropathy with pvalue 0.047 . In culprit only revascularization group the mean $\mathrm{LVEF}$ was $50.40 \pm 3.18$ while in total revascularization group the mean left ventricular ejection fraction (LVEF) was $51.36 \pm 4.37$ with p-value 0.155 .

Conclusios: Total revascularization can be done in primary PCI in selected cases (simple lesion, low thrombus burden), which is safe and less expensive than culprit only revasvularization by reducing the possibelity of further unplaned procedures.
\end{abstract}

Key words: Acute myocardial inferction, Multivessel diseases, primary PCI, Multivessel angioplasty.

\section{INTRODUCTION}

$\mathrm{C}$ oronary artery disease (CAD) is a major cause of mortality and morbidity in developed countries. Before developing the technique of PCI coronary artery bypass graft (CABG) had been the only standard revascularization procedure .Fortunately, there is an alternative treatment for CAD, the PCI which is effectives, safe less disabling and less expensive revascularization procedure compared with $\mathrm{CABG}^{(\mathbf{1})}$

Early restoration of normal coronary perfusion after myocardial infarction limits infract size, preserve left ventricular function and reduce mortality.

Although primary percutaneous coronary intervention (PPCI) is the most effective method of reperfusion for acute MI, Significant LV contractile dysfunction is still evident months after the index event in significant number of patient, ${ }^{(2,3)}$ while convalescent LV function is the strongest determinant of late survival after MI, the predictor of myocardial recovery in patient who are treated by contemporary PCI techniques have been incompletely characterized. ${ }^{(4,5)}$

Primary percutanous coronary intervention in acute myocardial infarction result in greater patency of infarct related artery and lower rates of death reinfarction and stroke when compared with fibrinolysis done.

Clinical evidence demonstrates that around $40-65 \%$ of patients with St-segment elevation myocardial infarction (STEMI) have angiographic documented multi vessel disease for these patients early revascularization of the culprit lesion by primary percutanous coronary intervention (PCI) is 
recommended according to recent guidelines. But strategy for treatment of non culprit lesion in this setting remain unclear. ${ }^{(6)}$

It seem reasonable to investigate an alternative strategy based on rapid relief of all significant lesions when dealing with multi vessel disease patient as an effort to promote collateral circulation $\&$ further limit the infracted size.

\section{AIM OF THE WORK}

To compare between primary PCI for culprit lesion only and that for both culprit and non culprit lesion in ST segment elevation MI patients with multi-vessel disease.

\section{PATIENTS AND METHODS}

This study included 50 patients presented to cardiology department Zagazig Unviersity and national heart institute with acute ST segment elevation myocardial infarction (STEMI) eligible for primary PCI.

Acute ST segment elevation myocardial infarction is detected by rise and /or fall in cardiac biomarkers (preferred troponin) with at least one value above 99th percentile of the upper reference limit with at least one of the following:

a) Symptoms of ischemia.

b) ECG changes of new ischemia (ST elevation or LBBB).

c) Development of pathological Q waves.

d) Imaging evidence of new loss of viable myocardium.

Criteria of AMI Adapted from (Thygesen et al., 2007) ${ }^{(7)}$.

The patients were divided into two groups

- $\mathbf{1}^{\text {st }}$ group: 25 patients were managed by primary percutaneous coronary intervention for infarct related artery only (culprit revascularization).

- $\mathbf{2}^{\text {nd }}$ group: 25 patients were managed by primary percutaneous coronary intervention for infarct related artery and non infart related artery (total revascularization).

Inclusion criteria:

All our patients:

A) Present with Acute ST-Segment elevation myocardial infarction (STEMI).

B) Have multi vessel coronary artery disease on angiography suitable for percutaneous coronary intervention.

\section{Multi vessel disease}

Defined as the presence of at least one lesion > $70 \%$ in major epicardial vessel, or one of its branches other than the infarct related artery (IRA).

\section{Exclusion criteria:}

1- Any contraindication for antiplatelet therapy.

All patients were subjected to:

1-Full history taking.

That includes the demographic data as age and gender,risk factors and the time between onset of symptoms to the first medical contact

2- Full clinical examination and risk assesment.

\section{3-Twelve lead surface ECG.}

With right ventricular leads (V3R,V4R) and posterior leads $(\mathrm{V} 7, \mathrm{~V} 8)$ when right ventricular and or posterior myocardial infarction were suspected.

\section{4-Blood samples for}

a- Cardiac enzymes b-Renal function tests

c- Random blood glucose

d- Complete blood picture

5. Echo Cardiography

Transthorthic echocardiography was done during admission and after Six months to assess ejection fraction

The echo machines that were used are Philips Envisor, Philips HD7,General electric Vivid 3 and General electric Vivid S5.

\section{Statistical Analysis}

Data were expressed as the mean $( \pm$ standard deviation) or median (interquartile range) for continuous variables, and number $(\%)$ for categorical variables. Patient characteristics between the 2 treatment groups (culprit and total re-vascularization) and associations between risk factors will be compared using a Student's t-test for normal continuous data, a Wilcoxon rank sum test for skewed continuous data, and a chi-squared test for categorical data. Data were analyzed using Statistical Program for Social Science (SPSS) version 18.0.

The following tests were done:

$\checkmark$ Independent-samples t-test of significance was used when comparing between two means.

Chi-square (X2) test of significance was used in order to compare proportions between two qualitative parameters.

$\square$ Probability (P-value)

- P-value $<0.05$ was considered significant.

- P-value $<0.01$ was considered as highly significant.

- P-value >0.05 was considered insignificant. 


\section{RESULTS}

A. Demographic data and risk factors

Table (1): Comparison between both studied groups as regard demographic data and comorbidities.

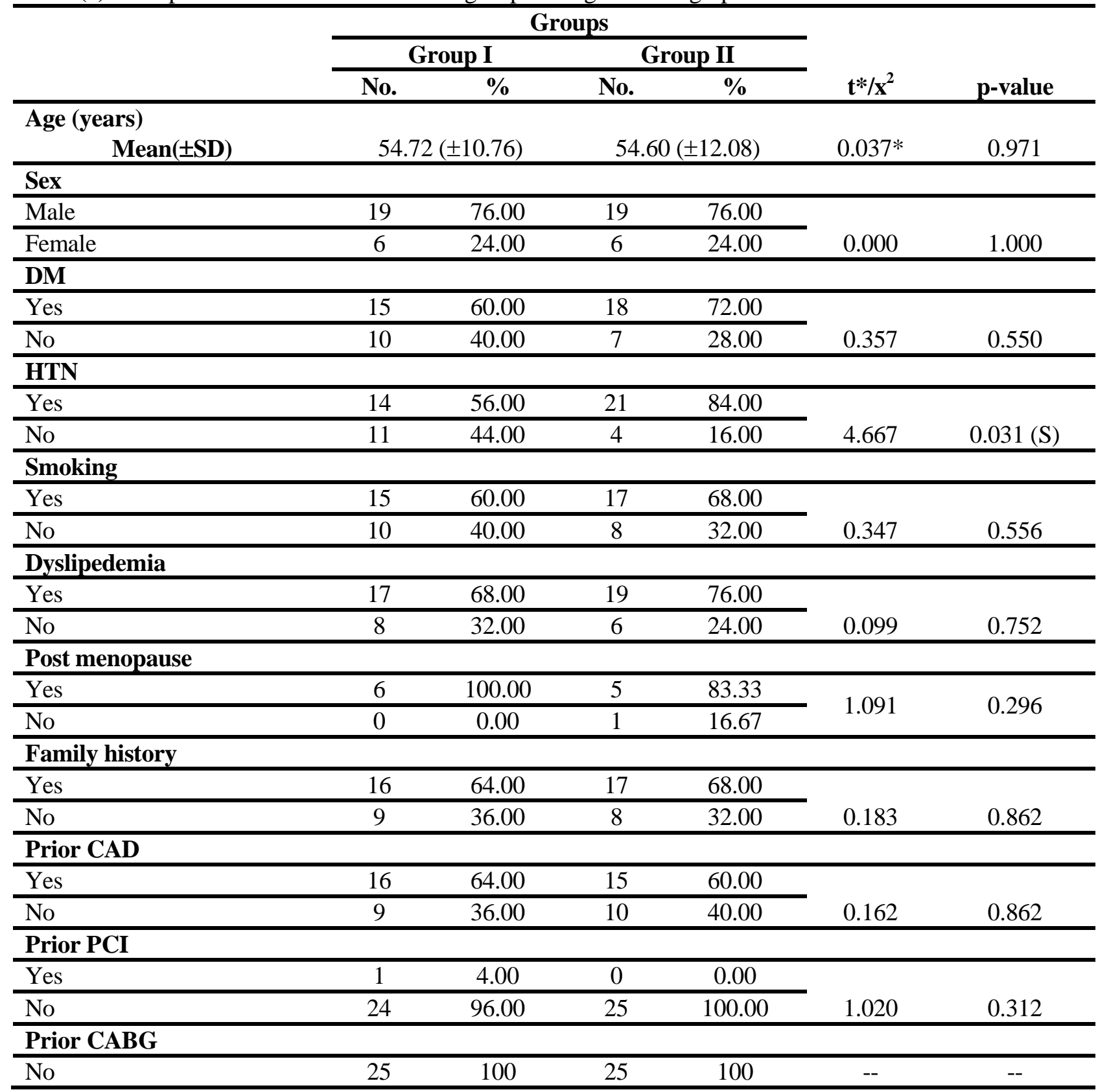

\section{* independent sample t-test}

This table shows that there was no statistically significant difference between both studied groups as regard age, sex, dibaites, smoking, post menopose, family history, dyslipidemia, prior CAD, prior PCI, prior $\mathrm{CABG}$ and there was statistically significant increase in hypertension in group (II) as compared to group (I) with p-value (0.031).

\section{B. Clinical and echocardiographic data and PCI} procedures.

1. Site of myocardial infarction according to ECG findings.

In group (I) $(36 \%)$ of the patients had inferior MI and (64\%) had anterior MI while in group (II)
(56\%) of the patients had inferior MI and (44\%) had anterior MI.

2. Time from onset of symptoms to hospital admission

In group (I) the mean time was $6.84 \pm 3.09$ and group (II) the mean time was $(5.92 \pm 2.78)$.

3. Time from door to balloon

In group (I) the mean time from door to ballon was $(64.40 \pm 30.83 \mathrm{~min}$.) while in group (II) mean time of door to ballon was $(78.80 \pm 44.47 \mathrm{~min}$.).

\section{In hospital complications}

In group (I) recurrent chest pain and angina occur in 13 patients (52\%), Arrhythmia, occuar in 3 patients $(12 \%)$, minor bleeding occur in 6 patients $(24 \%)$ contrast 
induced nephropathy (CIN) occur in 3 patients $(12 \%)$ and the following MACE (major bleeding, stent thrombosis, cardiogenic shock strock, reinfraction, further revascularization were no't observed in this patients, while in group (II) recurrent chest pain and angina occur in 5 patients (20\%), Arrhythmia, occuar in 3 patients (12\%), minor bleeding occur in 3 patients (12\%), CIN occur in 9 patients (36\%), stent thrombosis, occur in 2 patients (8\%) and further revascularization occur 2 patients (8\%) and the following MACE (major bleeding, , cardiogenic shock, strock) were not observed in this patients, there was statistically significant increase in CIN in group II as compared to group I $(p<0.05)$ and show the statistically significant increase in recurrent angina in group I ascompared to group II ( $\mathrm{p}=0.039)$.

Table (2): Comparison between both studied groups as regard in hospital complications

\begin{tabular}{|c|c|c|c|c|c|c|c|c|c|}
\hline \multirow{3}{*}{ Complications } & & \multicolumn{4}{|c|}{ Groups } & \multirow{2}{*}{\multicolumn{2}{|c|}{ Total }} & \multirow{2}{*}{\multicolumn{2}{|c|}{ Chi-square }} \\
\hline & & \multicolumn{2}{|c|}{ Group I } & \multicolumn{2}{|c|}{ Group II } & & & & \\
\hline & & No. & $\%$ & No. & $\%$ & No. & $\%$ & $\mathbf{x 2}$ & p-value \\
\hline Stroke & No & 25 & 100 & 25 & 100 & 50 & 100 & 0 & 1.000 \\
\hline \multirow{2}{*}{ Further revascularization } & Yes & 0 & 0.00 & 2 & 8.00 & 2 & 4.00 & \multirow{2}{*}{2.083} & \multirow{2}{*}{0.149} \\
\hline & $\mathrm{No}$ & 25 & 100.00 & 23 & 92.00 & 48 & 96.00 & & \\
\hline \multirow{2}{*}{$\begin{array}{c}\text { Contrast induced } \\
\text { nephropathy (CIN) }\end{array}$} & Yes & 3 & 12.00 & 9 & 36.00 & 12 & 24 & \multirow{2}{*}{3.947} & \multirow{2}{*}{$0.047(S)$} \\
\hline & No & 22 & 88.00 & 16 & 64.00 & 38 & 76 & & \\
\hline \multirow{2}{*}{ Minor bleeding } & Yes & 6 & 24.00 & 3 & 12.00 & 9 & 18 & \multirow{2}{*}{1.220} & \multirow{2}{*}{0.269} \\
\hline & No & 19 & 76.00 & 22 & 88.00 & 41 & 82 & & \\
\hline Major bleeding & No & 25 & 100 & 25 & 100 & 50 & 100 & 0 & 1.000 \\
\hline \multirow{2}{*}{ Arrhythmia } & Yes & 3 & 12.00 & 3 & 12.00 & 6 & 12 & \multirow{2}{*}{0} & \multirow{2}{*}{1.000} \\
\hline & No & 22 & 88.00 & 22 & 88.00 & 44 & 88 & & \\
\hline \multirow{2}{*}{ Recurrent angina } & Yes & 13 & 52.00 & 5 & 20.00 & 18 & 36 & \multirow{2}{*}{4.253} & \multirow{2}{*}{$0.039(S)$} \\
\hline & No & 12 & 48.00 & 20 & 80.00 & 32 & 64 & & \\
\hline Cardio genic shock & No & 25 & 100.000 & 25 & 100.000 & 50 & 100 & 0 & 1.000 \\
\hline \multirow{2}{*}{ Stent thromosis } & Yes & 0 & 0.00 & 2 & 8.00 & 2 & 4.00 & \multirow{2}{*}{2.083} & \multirow{2}{*}{0.149} \\
\hline & No & 25 & 100.00 & 23 & 92.00 & 48 & 96.00 & & \\
\hline \multirow{2}{*}{ Re infarct } & Yes & 0 & 0.00 & 2 & 8.00 & 1 & 2 & \multirow{2}{*}{1.020} & \multirow{2}{*}{0.312} \\
\hline & $\mathrm{No}$ & 25 & 100.00 & 23 & 92.00 & 49 & 98 & & \\
\hline \multirow{2}{*}{ Nothing } & Yes & 11 & 44.00 & 15 & 60.00 & 26 & 52 & \multirow{2}{*}{1.282} & \multirow{2}{*}{0.258} \\
\hline & No & 14 & 56.00 & 10 & 40.00 & 24 & 48 & & \\
\hline Renal failure & No & 25 & 100.00 & 25 & 100.00 & 50 & 100.0 & 0 & 1.000 \\
\hline
\end{tabular}

This table shows that there was statistically significant increase in CIN in group II as compared to group I ( $p<0.05$ ) and show the statistically significant increase in recurrent angina in group I ascompared to group II ( $\mathrm{p}=0.039)$. 


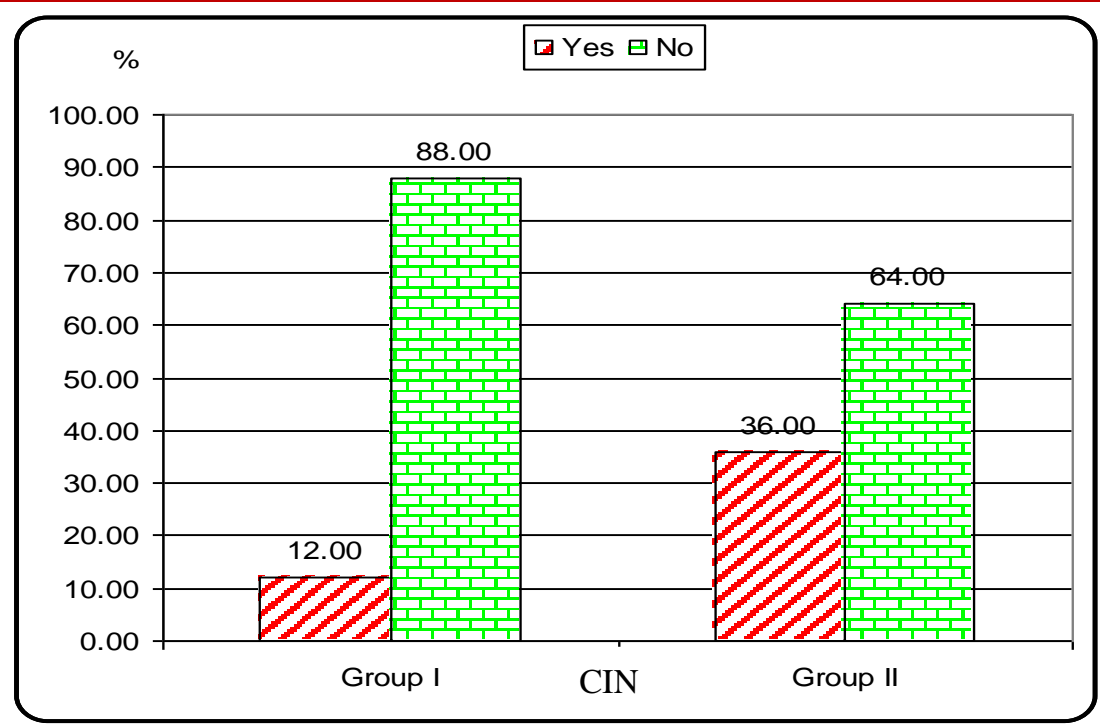

Fig. (1): Comparison between both studied groups as regard CIN.

This Fig. shows that there was statistically significant increase in CIN in group II as compared to group I $(p<0.05)$

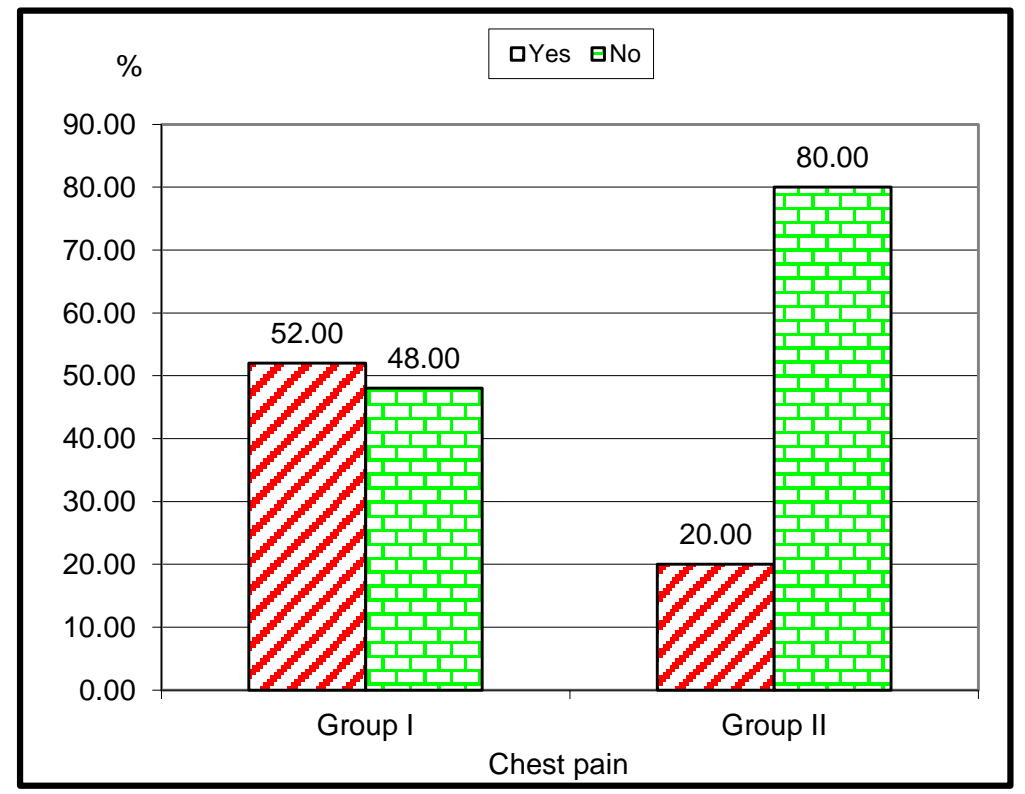

Fig. (2): Comparison between both studied groups as regard chest pain.

This fig. shows that there was statistically significant increase in recurrent angina in group I ascompared to group II $(\mathrm{p}=0.039)$.

5. Left ventricular ejection fraction (LVEF) before and 6 months after PPCI.

In group (I) the mean EF before primary PCI was $38.88 \pm 3.78$ and in group (II) the mean EF was (39.04 \pm 5.07$)$, while in group (I) the mean EF 6 months after primary PCI was $(50.04 \pm 3.18)$ and in group (II) the mean EF was (51.96 \pm 4.37$)$.

\section{PCI time}

In group (I) the mean PCI time was $(40.80 \pm 8.38 \mathrm{~min}$.) and in group (II) the mean PCI time was $(50.80 \pm 11.15 \mathrm{~min})$, there was highly statistically significant decrease in PCI time in group I as compaired to group II $(\mathrm{P}<0.001)$.

Table (3): Comparison between both studied groups as regard PCI time.

\begin{tabular}{cccccc}
\hline & \multicolumn{3}{c}{ PCI time (minute) } & \multicolumn{1}{c}{ t-test } \\
\cline { 2 - 6 } Groups & Mean & \pm SD & Mean Difference & t & p-value \\
\hline Group I & 40.80 & 8.38 & & & \\
\hline Group II & 50.80 & 11.15 & -10.00 & -3.585 & $<\mathbf{0 . 0 0 1}$ HS \\
\hline
\end{tabular}




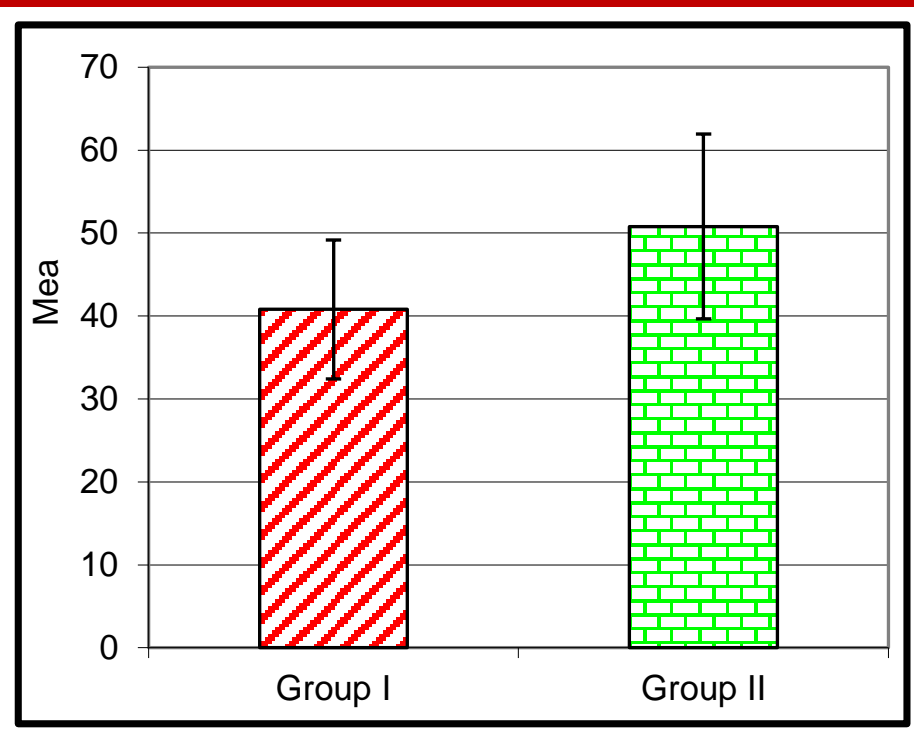

Fig. (3): Comparison between both studied groups as regard PCI time.

This table and fig. shows that there was highly statistically significant decrease in PCI time in group I as compaired to group II $(\mathrm{P}<0.001)$.

\section{PCI contrast}

In group (I) the mean PCI contrast $(\mathrm{mL})$ was $(166 \pm 68.8)$ and in group (II) the mean PCI contrast (mL) (266 \pm 55.38), there was higly statistically significant decrease in PCI contrast used in group I as compaired to group II $(\mathrm{P}<0.001)$.

Table (4): Comparison between both studied groups as regard PCI contrast (mL).

\begin{tabular}{cccccc}
\hline & \multicolumn{3}{c}{ PCI contrast $(\mathbf{m L})$} & \multicolumn{2}{c}{ t-test } \\
\cline { 2 - 6 } Groups & Mean & \pm SD & Mean Difference & t & p-value \\
\hline Group I & 166.00 & 68.80 & & & \\
\hline Group II & 266.00 & 55.38 & -100.00 & -5.661 & $<\mathbf{0 . 0 0 1}$ HS \\
\hline
\end{tabular}

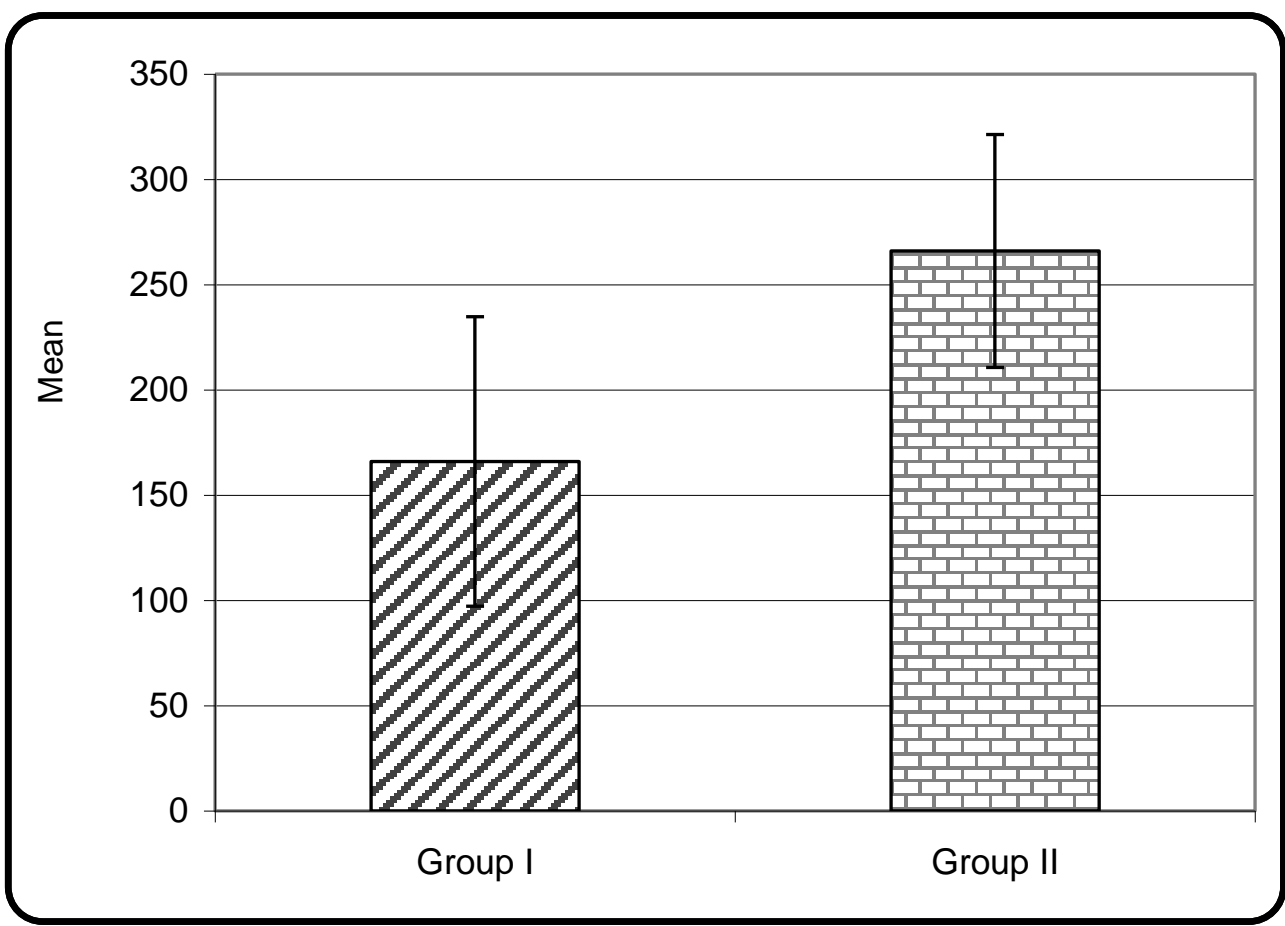

Fig. (4): Comparison between both studied groups as regard PCI contrast (mL).

This table and fig. shows that there was higly statistically significant decrease in PCI contrast used in group I as compaired to group II $(\mathrm{P}<0.001)$.

\section{PTCA using ballon dilatation}


In group (I) (44\%) of the patients had done ballon dilatation while in group II (68\%) of the patient had done ballon dilatation.

\section{DISCUSSION}

PCI is currently the treatment of choice in patients with STEMI. CAD is a diffuse process and patients presenting with a coronary syndrome in 20 $40 \%$ of cases have multiple significant coronary lesions, which confer a substantially increased risk of cardiovascular morbidity and mortality. ${ }^{(\boldsymbol{(})}$

Recent studies, suggest that acute coronary syndromes, including AMI, may result from a systemic inflammatory process, causing multiple unstable lesions. Thus, a strategy of multivessel PCI in the peri-infarct period may be important in improving the outcomes of primary angioplasty. ${ }^{(\mathbf{8})}$

Such an attempt of complete revascularization may prevent recurrent ischemia from 'non-infarctrelated' lesions, obviating the need for repeat angiography and intervention, and also possibly improves the late outcome by reducing the ischemic burden following myocardial damage. ${ }^{(9)}$ Contemporary guidelines recommend dilating only the IRA during the urgent procedure, leaving the other stenosed vessels untreated (culprit-only revascularisation) or to dilate during a second elective procedure (staged revascularisation). Simultaneous treatment of IRA and non-IRA is recommended only in patients with cardiogenic shock. ${ }^{(\mathbf{1 0})}$ However, these guidelines are based on the results of earlier studies. With advancing technology and newer antiplatelet drugs, outcomes have improved even in patients undergoing multivessel and higher-risk elective procedures. ${ }^{(11)}$ Yet, few reports have described outcomes of multivessel compared with IRA-only revascularisation in patients undergoing urgent mechanical reperfusion for STEMI. ${ }^{(\mathbf{1 2})}$ Therefore, the optimal management of patients with multivessel disease in this setting still unclear.

The aim of this study was to compare between primary PCI in patients with STEMI and multivessel CAD: culprit only revascularization (group I) and simultaneous treatment of IRA and non IRA (total revascularization) (group II).

The risk factors of patients in our study were higher than the risk factors of patients in other studies as Toma et $\boldsymbol{a l} .{ }^{(\boldsymbol{( 6 )}}$ in which COR group had $20 \%$ diabetes mellitus, $55 \%$ had hypertension. While in TR group 19\% had diabetes mellitus, 54\% had hypertension. So as regarding comorbidities the risk of patients in our study was higher than other trials and this may have affected the out come.

We found that there was statistically significant increase in hypertension in total revascularization group (p-value 0.031 ) which may be a predesposing factor to increase contrast induced nephrotpathy in total revascularization group.
There was no staitstically significant difference between both studied groups as regard time from onset of symptoms to admission where the time was $6.84 \pm 3.09$ hours in COR group, while in TR group was5.92 \pm 2.78 hours.

This was discordant with Di Mario et al. ${ }^{(13)}$ in which time from onset of symptoms till hospital arrival was $167 \pm 180 \mathrm{~min}$ in COR and $122 \pm 97 \mathrm{~min}$ in TR group,This difference can be explained by delayed diagnosis, delayed contact with the operator and lack of facilities.

There is increased incidence of inferior MI in TR group than COR group as inferior wall MI represent $56 \%$ in TR group while $36 \%$ in COR group, however this did not reach statistical significance. This is discordant with other studies as Rigattieri et al. $^{(\mathbf{1 4})}$ in which TR group that included 46patients anterior wall MI represent 56\%. While COR group that included 64 patients anterior wall MI represents 39\%, however this was concordant with Varani et al. ${ }^{(\mathbf{1 5 )}}$ that included 346 patients in COR group in which anterior wall MI represents 49\% while in TR group that included 399 anterior wall MI represents $42 \%$.

In COR group culprit vessel is LAD in $64 \%$, RCA in $28 \%$ and LCX in $8 \%$ while in TR group culprit vessel is LAD $44 \%$, RCA in $48 \%$ and LCX in $8 \%$.Other studies as Varani et al. ${ }^{(\mathbf{1 5})} \mathrm{COR}$ group that included 346 patients, LAD represent 52\%, RCA $37 \%$, LCX $11 \%$, while TR group that included 399 patients LAD represent $40 \%$, RCA $39 \%$ and LCX $18 \%$.

The number of non infarct related artery was single vessel in $68 \%$, two vessel in $32 \%$ of both group, this was disconcordant with other studies as Chen et $\boldsymbol{a \boldsymbol { l } ^ { ( \mathbf { 1 6 } ) }}$ in which non IRA were single vessel in $52 \%$ of COR group and $42 \%$ of TR group while two vessel disease occurred in $48 \%$ of COR group and in $58 \%$ of TR group.

There was statistically significant diference between the two group as regard mean PCI time/ min as the mean PCI time/min in group II was $50.8+11.5$ versus $40.8+8.3$ in group I ( $\mathrm{p}$ value $<0.001$ ). Also there was statistically significant diference between the two group as regard the mean PCI contrast $/ \mathrm{ml}$ as the mean PCI contrast in group II was $266+55.38 \mathrm{ml}$ versus $166+68.8 \mathrm{ml}$ in group I .This was concordant with other studies As Di mario et al. ${ }^{(\mathbf{1 3})}$ in which in TR group the mean PCI time/min was $69+38 \mathrm{~min}$ and mean PCI contrast was $341+163 \mathrm{ml}$ while in COR group the mean PCI time/min was 53+24 min and mean PCI contrast was $242+106 \mathrm{ml}$.

As regard stent thrombosis it was occurred in 2 cases in TR group while it didn't occur in COR group and this didn't reach a statistically significant 
difference, while there was increased incidence of recurrent chest pain in COR group (recurrent chest pain occurred in 52\% of COR group versus $20 \%$ of TR group and this difference was statistically significant ( $\mathrm{P}$ value $=0.039$ ), and this decrease in recurrent angina and chest pain in TR group improve the quality of life and reduce the need for further revasculerization.

There was statistically significant increased in contrast induced nephropathy in TR group (CIN occurred in $36 \%$ of TR group versus $12 \%$ of COR group), this is because of using large amount of contrast medium which mostly was ionic contrast. This was concordant with Marenzi et al. $^{(\mathbf{1 7})}$ that reported a higher rate of CIN (19\%) in 208 patients with STEMI undergoing total revascularization during PPCI.

Contrast induced nephropathy had occurred more in patients that had done PCI to more than one vessel other than the culprit vessel than in patients which had done PCI to only one vessel other than the culprit vessel ,and this may be explained by the usage of larger amount of contrast medium which mostly was ionic contrast. Also contrast indused nephropathy had occurred in patients that had more risk factors like diabetis and hypertension , and in patients that had more complex lesions in the non infarcted related artries which prolong the duration of the procedure and increase the amount of dye used during the procedure,and in our study no one of the patients who had contrast indused nephropathy needs dialysis on further follow up, the incidence of contrast indused nephropathy can be redused by adequete hydration of the patient,administration of low osmolar contrast media,limitation of contrast dose and a combination prophylaxis of $\mathrm{N}$-acetyle cystiene and $\mathrm{NaHco3}$ adminestration according to the ejection fraction and killip class.

These results were concordant with the studies comparing both groups as:

Ijsselmuiden et al. ${ }^{(11)}$ who found that multivessel approach had better outcome by decreasing the need for further revascularization.

Also Kong et $\boldsymbol{a l} .^{(\mathbf{1 8})}$ found that multivessel angioplasty during acute myocardial infarction may be safe compared with PCI to infarcted related artery. Qarawani et al. ${ }^{(\mathbf{1 9 )}}$ observed that patients underwent total revascularization during PPCI had lower incidence of further revascularization. Also Politi et $\boldsymbol{a l} \boldsymbol{l}^{(\mathbf{8})}$ suggested that the multivessel approach is safe and possibly less expensive than an incomplete approach by reducing the probability of further unplanned procedures and without affecting the length of hospitalization.

Also Chen et al. ${ }^{(16)}$ found that short term, long term survival and cardiac events rates in patients undergoing multivessel PCI are similar to those in patients undergoing single vessel intervention (IRA).

However this was discordant with other trials, as Corpus et al. $^{(\mathbf{2 0 )}}$ revealed that 30 days follow up of patients underwent TR had more fatal re-infarction and more MACEs than patients undergoing COR strategies. Also Moreno et al. ${ }^{(21)}$ found that patients with MVD undergoing TR during primary angioplasty for STEMI, had higher rate of in hospital \&30 days mortality than those undergoing COR strategy.

Also Hannan et al. ${ }^{(22)}$ found that patients with multivessel disease STEMI undergoing multivessel primary PCI at the time of the index procedure had mortality rates that were higher than rates for patients with culprit vessel PCI alone.

As regard the previous data we found that old trials suggest that COR strategy is the best, while many new trials suggest that TR strategy can be done safely with less need to further revascularization, this may be explained by improvement in PCI techniques, aspiration devices, medication as glycoprotein IIb/IIIa inhibitors and newer generation of stents.

\section{CONCLUSIOS}

Total revascularization can be done in primary PCI in selected cases (simple lesion, low thrombus burden), which is safe and less expensive than culprit only revasvularization by reducing the possibelity of further unplaned procedures.

\section{REFERENCES}

1. Cook S, Walker A, Hugll O et al (2007) Percutaneous coronary interventions in Europe. Preveralence, numerical estimates, and Projections based on data up to 2004. Clin Res Cardiol 96:375382.

2. Keeley EC Boura JA, Grines CL. primary angioplasty versus intravenus thrombolytic therapy for acute myocardial infarction : A quantitative review of 23 randomized trail. Lancet 2003 ; 361:13-20.

3. Ottervanger JP, Van`t Hof AW, Reiffers et al. Long term recovery of Left ventricular function after primary angioplasty for acute myocardial infarction. Eur Heart Journal 2002; 39:30-36

4. Halkin A, Stone GW, Dixon SR, et al. Impact and determinants of left ventricular function in patients undergoing primary percutaneous coronary intervention in acute myocardial infarction Am J Cardiol 2006; 96:325-331.

5. Burns RJ, Gibbons RG Yi Q et al for the CORE study Investigator. the relation ship of left ventricular ejection fraction, end-systolic volume index and infarct size to six-month mortality after hospital discharge following myocardial infarction treated by thrombolysis. J Am Coll Cardiol 2002 ; 39:30-36 
6. Toma M, Christopher E. Buller et al. Non- Culprit Coronary artery percutaneous coronary intervention during acute ST-segment elevation myocardial infarction : insights from the APEXAMI trial. Eur Heart Journal $2010 ; 31: 17011707$.

7. Thygesen K, Alpert JS, White HD. (2007): Joint ESC/ACCF/AHA/WHF Task Force for the Redefinition of Myocardial Infarction. Universal definition of myocardial infarction.Eur Heart $\mathrm{J}$; 28:2525

8. Politi L, Sgura F, Rossi R, et al. (2010): A randomised trial of target-vessel versus multivessel revascularizationin ST-elevation myocardial infarction: major adverse cardiac events duringlong-term follow-up. Heart; 96:662-667.

9. Goldstein JA, Demetriou D, Grines CL, et al. (2000): Multiple complex coronary plaques in patients with acute myocardial infarction. $\mathrm{N}$ Engl $\mathrm{J}$ Med; 343:915e22.

10. Smith SC Jr, Feldman TE, Hirshfeld JW Jr, et al. (2006): ACC/ AHA/ SCAI 2005 Guideline Update for Percutaneous Coronary Interventiondsummary article: a report of the American College of Cardiology/ American Heart Association Task Force on Practice Guidelines (ACC/ AHA/ SCAI Writing Committee to Update the 2001 Guidelines for Percutaneous Coronary Intervention). Circulation; 113:156e75.

11. Ijsselmuiden AJ, Ezechiels J, Westendorp IC, et al. (2004): Complete versus culprit vessel percutaneous coronary intervention in multi vessel disease: a randomized Jeart J 2004; 148: 467-474.

12. Roe MT, Cura FA, Joski PS, et al. (2001): Initial experience with multivessel percutaneous coronary intervention during mechanical reperfusion for acute myocardial infarction. Am J Cardiol; 88:170e3; A6.

13.Di Mario C, Sansa M, Airoldi F et al. (2004): Single versus multivessel treatment during primary angioplasty: results of the multicentre randomized Hzpecoat" -for culprit or multivessel stenting for Acute Myocardial Infarction (HELP AMI) Study. Int I Cardiovase Intervent; 6:128-133.
14. Rigattieri $S$, Biondi-Zoccai $G$, Silvestri $P$, et al. (2008): Management of multivessel coronary disease after ST elevation myocardialinfarction treated by primary angioplasty. J Interv Cardiol; 21:1-7.

15. Varani E, Balducelli M, Aquilina M, et al. (2008): Single or multivessel percutaneous coronary intervention in ST-elevation myocardialinfarction patients. Catheter CardiovascInterv; 72:927-933.

16. Chen LY, Lennon RJ, Grantham JA, et al. (2005): In-hospital and long-term outcomes of multivessel percutaneous coronaryrevascularization after acute myocardial infarction. Am J Cardiol; 95: 349-354.

17. Marenzi G, Assanelli E, Campodonico J, et al. (2009): Contrast volume during primary percutaneous coronary intervention and subsequent contrast-induced nephropathy and mortality. Ann Intern Med.; 150:170-177.

18. Kong JA, Chou ET, Minutello RM, et al. (2006): Safety of single versusmulti-vessel angioplasty for patients with acute myocardial infarction and multivesselcoronary artery disease: report from the New York State Angioplasty Registry. Coron Artery Dis; 17:71-75.

19. Qarawani D, Nahir M, Abboud M, et al. (2007): Culprite only versus complete coronary revascularization during primary PCI.IntJ cardiol, 123:288-292.

20. Corpus RA, House JA, Marso SP, et al. (2004): Multivessel percutaneous coronary intervention in patients with multivessel disease and acute myocardial infarction. Am Heart J; 148:493-500.

21. Moreno R, Garcia E, Elizaga J, et al. (1998): Results of primary angioplasty in patients with multivessel disease. Rev Esp Cardiol; 51:547-555.

22. Hannan EL, Samadashvili Z, Walford G, et al. (2010): Culprit vessel percutaneous coronary interventionversus multivessel and staged percutaneous coronary intervention for STsegment elevation myocardial infarction patients with multivessel disease. JACC Cardiovasc Interv; 3:22-31. 